\title{
Motivation, Learning Strategies, and Performance in Physical Education at Secondary School
}

\author{
Svein Olav Ulstad ${ }^{1}$, Hallgeir Halvari ${ }^{2}$, Øystein Søreb $\emptyset^{2}$, Edward L. Deci ${ }^{2,3}$ \\ ${ }^{1}$ Department of Physical Education and Sport Science, North University, Levanger, Norway \\ ${ }^{2}$ School of Business and Social Sciences, University College of Buskerud and Vestfold, Hønefoss, Norway \\ ${ }^{3}$ Department of Clinical and Social Sciences in Psychology, University of Rochester, Rochester, NY, USA \\ Email: svein.o.ulstad@nord.no
}

Received 23 November 2015; accepted 11 February 2016; published 14 February 2016

Copyright (C) 2016 by authors and Scientific Research Publishing Inc.

This work is licensed under the Creative Commons Attribution International License (CC BY). http://creativecommons.org/licenses/by/4.0/

(C) () D Den Access

\begin{abstract}
Field studies investigating self-determined motivation in relation to learning strategy use and its educational outcomes in physical education are lacking. The purpose of the present study was therefore to test a Self-Determination Theory (SDT; Deci \& Ryan, 2000) process model of learning strategy use as it related to participation and performance in physical education courses in eighth through tenth grades. In this model, autonomy support from teachers was hypothesized to be positively related to basic psychological need satisfaction. In turn, need satisfaction was expected to be positively related to autonomous motivation and perceived competence, both of which should be positively related to learning strategy use. Finally, learning strategy use was hypothesized to be positively related to the level of participation and the performance (i.e., grades) in physical education courses. Structural equation modeling supported the SDT process model. All indirect links in the structural model were also significant.
\end{abstract}

\section{Keywords}

Self-Determination Theory, Need Satisfaction, Motivation, Performance, Autonomy Support, Learning Strategies, Physical Education

\section{Introduction}

The aim of the present article is to study the role of learning strategies in the relation between motivation and outcomes such as participation and performance in physical education. Abilities and skills are important, al- 
though not sufficient for achievement in school. Self-regulated motivation and learning strategies are also important (Schunk, 2005). In physical education, one of the main purposes is to facilitate students' understanding and acceptance of the importance of effort in reaching their goals, and to facilitate their experience of joy and coping by being actively engaged with others. A precondition in physical education is that all the students participate and contribute to each other's learning. Competence and effort are the bases for assigning grades in physical education. If students show persistence, trying to solve challenges without giving up, and work with others, contributing to their learning, it can enhance their grades. Learning strategies such as effort regulation, peer learning, and help seeking may not only help students get better grades but may also help them reach the main goals presented in the curriculum.

In the present research, learning strategies include effort regulation, help seeking, and peer learning (Nisbet \& Shucksmith, 1986; Pintrich, 2000), as well as task absorption (Elliot, Murayama, \& Pekrun, 2011). These learning strategies are important because they can enhance students learning and competence development (Weinstein \& Mayer, 1986), and the use of learning strategies has been found to be positively related to academic achievement (Pintrich, Smith, Garcia, \& McKeachie, 1993).

Self-Determination Theory (SDT; Deci \& Ryan, 2000) provides a potential perspective on the student-motivational antecedents of learning-strategy use and performance-related outcomes. The SDT motivation constructs of autonomous motivation and perceived competence have been found to predict a range of behavior change and learning outcomes (e.g., Williams \& Deci, 1996; Williams, Saizow, Ross, \& Deci, 1997), as well as participation and performance in physical education (Moreno, González-Cutre, Martín-Albo, \& Cervelló, 2010; Sas-Nowosielski, 2008; Ntoumanis, 2005). Ntoumanis \& Standage (2009) present an overview of studies from school physical education that has used SDT. Furthermore, many studies have shown relations from both authority figures' autonomy support and participants' need satisfaction to autonomous motivation and perceived competence (Bagøien, Halvari, \& Nesheim, 2010; Cheon, Reeve, \& Moon, 2012; Koka \& Hagger, 2010; Moreno-Murcia, Lacarcel, \& Alvarez, 2010), as well as to engagement and performance in physical activity (Chatzisarantis \& Hagger, 2009) or physical education (Tessier, Sarrazin, \& Ntoumanis, 2010). Thus, it seems that the antecedents of learning strategies in our model have received support from past studies. Because it is sensible to predict that autonomy support and need satisfaction will predict autonomous motivation and perceived competence, and that autonomous motivation and perceived competence will predict the learning strategies and outcomes. Learning strategy research from a SDT perspective is scarce. However, motivational constructs similar to autonomous motivation such as mastery goals have been positively related to learning strategy use (Hofer, Yu, \& Pintrich, 1998), and both autonomous motivation and perceived competence have been positively linked to the more specific learning strategy effort regulation (Miserandino, 1996; Vallerand \& Bissonnette, 1992). In addition, learning strategies have been positively linked to educational outcomes (Crede \& Phillips, 2011). This may indicate a mediating role of learning strategies in the relation between SDT motivation constructs and physical education outcomes, because both needs satisfaction and autonomous motivation have been positively linked to engagement and performance in physical education (Cheon, Reeve, \& Moon, 2012). In addition, in accordance with the SDT process model (Deci \& Ryan, 2000), we include perceived autonomy support from teachers and psychological needs satisfaction as antecedents of autonomous motivation and perceived competence in the model tested. This resulted in the following three questions: Would need satisfaction mediate the link between autonomy support and the two motivational constructs (viz., autonomous motivation and perceived competence)? Would the two motivational constructs mediate the links between needs satisfaction and the use of learning strategies? And would learning-strategy use mediate the relation between the two motivation variables and performance and participation in physical education?

The purpose of this study was to test the fit of a process model in which perceived autonomy support from teachers would positively predict students' need satisfaction, and that need satisfaction would positively predict both autonomous motivation and perceived competence, each of which in turn would be positively linked to learning strategy use, which again would positively predict both participation and performance (see Figure 1).

\subsection{Autonomy Support and Need Satisfaction}

In the educational domain autonomy support is defined as interpersonal sentiments and behaviors teachers provide during instructions to identify, nurture, and develop students' inner motivational resources (Reeve, 2009). To nurture inner motivational resources by providing explanatory rationales, relying on non-controlling and 


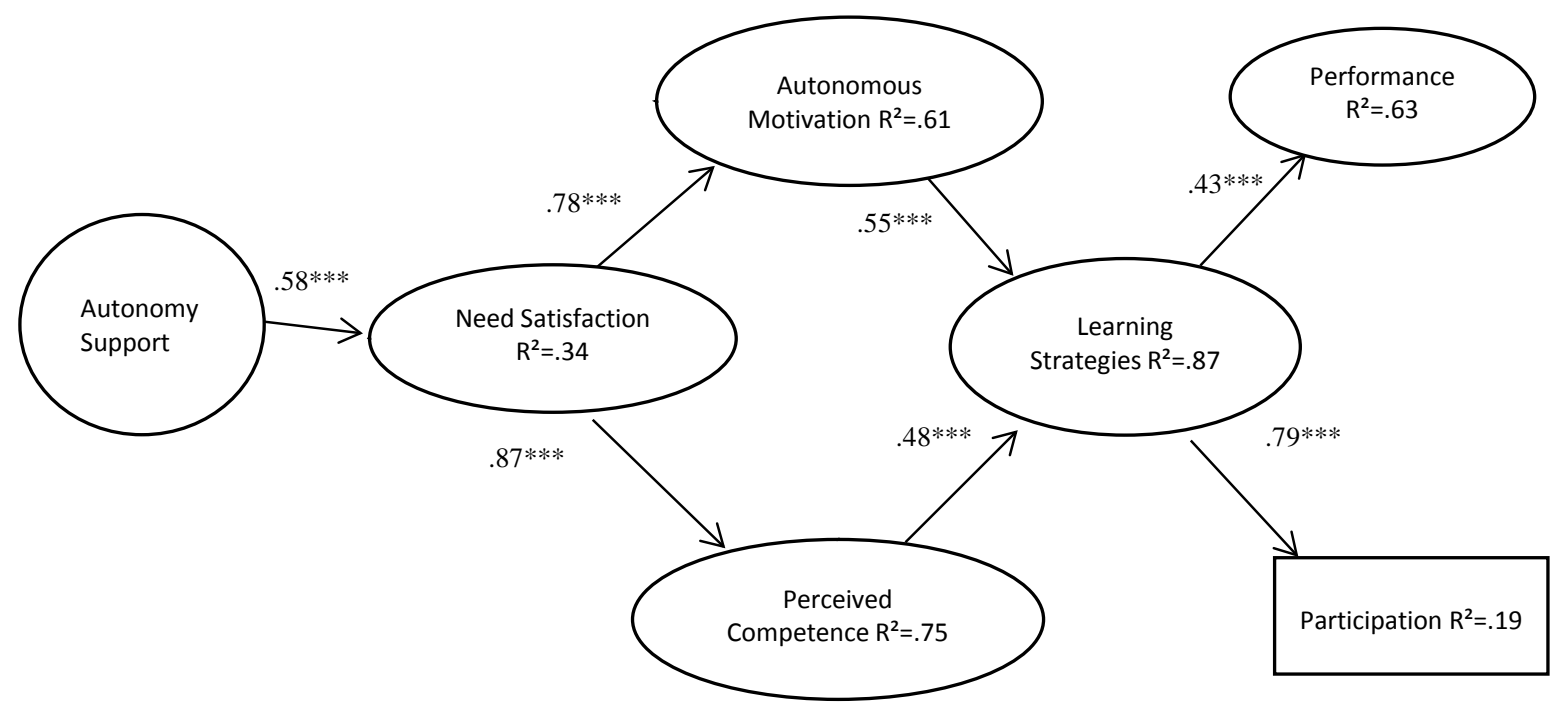

Figure 1. Results from the structural equation analysis. Note. All coefficients are standardized. $\chi^{2}(d f=182)=431.89, p$ $<.001$, RMSEA $(90 \% \mathrm{CI})=.069(.060-.077)$, CFI $=.93, \mathrm{TLI}=.92, \mathrm{SRMR}=.059, * * * p<.001$.

informational language, displaying patience to allow time for self-paced learning, and acknowledging and accepting expressions of negative affect (Reeve, 2009), teachers may be able to foster greater need satisfaction in students.

Teachers providing autonomy support have been shown both to nurture satisfaction of the needs for competence, relatedness, and autonomy in physical education (Cheon et al., 2012; Standage, Duda, \& Ntoumanis, 2006), and to predict perceived competence and autonomous motivation in high school students (Hardre \& Reeve, 2003).

\subsection{Need Satisfaction, Autonomous Motivation, and Perceived Competence}

Self-determination theory emphasizes that three inner needs are central to human growth and development, the needs for autonomy, competence, and social relatedness (Ryan \& Deci, 2002). Autonomy refers to volition and the experience of freedom (Deci \& Ryan, 2000). Competence is about feeling effective and confident in pursuing an activity (Ryan \& Deci, 2002), and relatedness is about being accepted by others and feeling connected to others in a secure environment (Ryan \& Deci, 2002). An autonomy supportive learning environment plays a key role in the satisfaction of these needs. According to the theory, satisfaction of these needs supports intrinsic motivation, internalization, and autonomous motivation (Ryan, Williams, Patrick, \& Deci, 2009). In an educational setting, students' often encounter activities they do not enjoy or that they find of little interest. Internalization of extrinsic motivation is therefore important for the students to maintain volition for those activities (Niemiec \& Ryan, 2009). By supporting the needs for competence, relatedness, and autonomy in physical activities, teachers can enable the process of internalization and integration of motivation (Ryan, Williams, Patrick, \& Deci, 2009). By supporting students' inner needs, teachers' can facilitate their autonomous self-regulation for learning and academic performance (Niemiec \& Ryan, 2009). Research in physical education has shown that satisfaction of each of the three needs predicts autonomous motivation independently (Koka \& Hagger, 2010; Standage, Duda, \& Ntoumanis, 2006) as does the sum of the three needs (Ntoumanis, 2005). Further, the need satisfactions correlated strongly positively with students' perceived competence for physical activity (Bagøien, Halvari, \& Nesheim, 2010). Other research in schools indicated that the needs for competence and autonomy are most important in relation to autonomous motivation (Barkoukis, Hagger, Lambropoulos, \& Tsorbatzoudis, 2010; Standage \& Gillison, 2007; Standage, Gillison, Ntoumanis, \& Treasure, 2012). Thus, because autonomy support has been directly linked to both autonomous motivation (Cheon, Reeve, \& Moon, 2012) and perceived competence (Moreno-Murcia, Lacarcel, \& Alvarez, 2010), we expected that satisfaction of the basic needs in physical education would mediate the positive links between autonomy support and both autonomous motivation and perceived competence. 


\subsection{Autonomous Motivation, Perceived Competence, and Learning Strategies}

Self-determined forms of extrinsic motivation (identified and integrated regulation) have been combined with intrinsic regulation to form autonomous motivation (Ryan \& Deci, 2000). SDT views the quality of motivation as more important than the amount of motivation for predicting outcomes, and a central distinction in SDT, namely, the degree to which motivation is autonomous versus controlled, is a critical differentiation in terms of quality of motivation. Autonomous motivation is when people have identified with the value of the activities and have integrated the internalizations into their own sense of self (Deci \& Ryan, 2008). Autonomous motivation is expected to lead to many positive outcomes such as long-term persistence, healthier behavior, and more effective performance (Deci \& Ryan, 2008). Empirical evidence based on self-determination theory research shows that autonomous motivation and intrinsic motivation are important for engagement and optimal learning in school (Niemiec \& Ryan, 2009). Autonomous motivation and perceived competence are believed to be critical preconditions for maintaining a behavior change over time (Ryan \& Deci, 2000), which is significantly less achieved when the motivation is controlled. Several studies of pupils and students from early elementary school to college and university have supported the hypothesis that changes in autonomous motivation and perceived competence would predict positive changes in: (1) classroom engagement, perceived skill, and performance in physical education (Cheon et al., 2012); (2) remaining in school and not dropping out (Vallerand \& Bissonnette, 1992); (3) the degree of conceptual learning and better memory of learned materials (Grolnick, Ryen, \& Deci, 1991); (4) improved academic achievement (Grolnick, Ryan, \& Deci, 1991; Miserandino, 1996); and (5) involvement in physical activity (Bagøien \& Halvari, 2005).

Learning strategies, in the present study, are operationalized as a composite of effort regulation, help seeking, and peer learning from the resource management strategies in the MSLQ manual (Pintrich, Smith, Garcia, \& McKeanchie, 1991), as well as task absorption. All variables are hypothesized to mediate between each of the two motivation variables and educational outcomes. In particular effort regulation seems to be of importance as significant relations have been reported for: (1) both autonomous motivation and/or perceived competence among students, in relation to persistence (i.e., effort when things become difficult) and involvement in class (Miserandino, 1996; Vallerand \& Bissonnette, 1992); (2) both autonomous motivation and perceived competence as predictors of continued effort at difficult tasks (viz., action orientation after failure) (Halvari, Ulstad, Bagøien, \& Skjesol, 2009); (3) both autonomous types of motivation and/or perceived competence and effort (Noels, Clement, \& Pelletier, 1999; Ntoumanis, 2001; Ntoumanis, 2002); (4) both autonomous motivation and need satisfaction in physical education and increases in effort over time (Taylor, Ntoumanis, Standage, \& Spray, 2010); and (5) autonomous motivation (both intrinsic and identified regulation) for goals and sustained effort over time in two studies of undergraduate students in psychology classes (Sheldon \& Elliot, 1998). Further, the strategy of task absorption (or concentration) represents cognitive immersion in an activity (Cury, Elliot, Sarrazin, Da Fonseca, \& Rufo, 2002), and has been positively correlated with autonomous motivation and participation (Martin \& Jackson, 2008). However, physical education research on peer learning and help seeking in a physical education context using self-determination theory seem scarce. Thus, autonomous motivation and perceived competence were expected to be positively linked to learning strategies, in particular to effort regulation and task absorption or concentration.

Because the use of learning strategies has been shown to be more evident among students with high normative ability in the academic classroom (Ames \& Archer, 1988), we also tested the relative contribution of normative ability (viz. grades/performance), autonomous motivation, and perceived competence in relation to the use of learning strategies. If motivation affects the use of learning strategies independent of ability this would be important, because there is evidence that it is much easier to influence students' motivation than their relatively more-stable abilities (Dweck, 1999).

\subsection{Links from Learning Strategies to Participation and Performance}

Effort regulation is important to academic success because it not only signifies goal commitment, but also regulates the continued use of learning strategies (Pintrich, Smith, Garcia, \& McKeanchie, 1991). Effort regulation is one of the resource management strategies that work as motivational beliefs that promote and sustain different aspects of self-regulated learning (Pintrich, 1999).

Peer learning has been found to have positive relations to achievement, and dialogue can help clarify material and reach insights one may not have attained on one's own (Pintrich, Smith, Garcia, \& McKeanchie, 1991). 
Help seeking from peers and the instructor is another important aspect of the environment. There is a lot of research that indicates that peer help, peer tutoring, and individual teacher assistance facilitate student achievement (Pintrich, Smith, Garcia, \& McKeanchie, 1991).

Task absorption helps people concentrate on an activity. It is a type of mental focus shown to be positively related to performance and enjoyment for students (Lee, Sheldon, \& Turban, 2003). Task absorption or involvement has been shown to be positively associated with intrinsic motivation and to lead to more free-choice puzzle solving, more time spent on the activity, and enjoyment (Cury, Elliot, Sarrazin, Da Fonseca, \& Rufo, 2002; Elliot \& Harackiewicz, 1996). A positive correlation between absorption and participation in art education was reported from university students (Wild, Kuiken, \& Schopflocher, 1995). An experience of absorption on the internet was shown to be more important than extrinsic factors regarding consuming behavior on the net (Shang, Chen, \& Shen, 2005).

A study among medical students reported significant positive associations between study effort and academic performance (grades) for males (Kusurkar, Ten Cate, Vos, Westers, \& Croiset, 2012). Another study report that effort-regulation strongly predicted course grades for freshman and upper level college students (Lynch, 2006). Two studies done by Sheldon \& Elliot (1998) showed that effort promotes goal attainment for students in a psychology class. A meta-analytic review of learning strategies, based on 67 independent samples indicates that effort-regulation was the one positively predicting grades most strongly (true score correlation $=.40)($ Crede \& Phillips, 2011). Analysis indicated that effort-regulation partially mediated the relationship between self-efficacy and grades. As self-efficacy is a similar construct, although more task specific, but related to perceived competence, this finding indicates that effort regulation may mediate the link between perceived competence and outcomes in the present study. Together with help-seeking and self-efficacy, effort regulation predicted $18 \%$ of the variance in grades for undergraduates (Komarraju \& Nadler, 2013). Effort as a learning strategy predicted final grades and performance in the lab among college students (Lynch, 2010).

\subsection{Model and Hypotheses}

Based on the theory and research described above, we tested a SDT (Deci \& Ryan, 2000) process model of participation and performance in physical education at school (see Figure 1). In the model, the hypothesized mediators are: (1) needs satisfaction would mediate the positive links between perceived autonomy support and each of the two motivation variables (autonomous motivation and perceived competence); (2) autonomous motivation and perceived competence would separately mediate the positive link between needs satisfaction and use of learning strategies; and (3) learning strategies would mediate the positive links between each of the two motivation variables and each of the two outcomes (viz., participation and performance in physical education).

We also tested the relative contribution of normative ability (grades) together with autonomous motivation and perceived competence in relation to the use of learning strategies.

\section{Method}

\subsection{Participants}

Participants were 290 students (162 boys and 128 girls) attending the 8th, 9th, or 10th grade (Mage = 14.0, SD $=.9$ ). The students were distributed among four schools in Nord-Trøndelag, Norway, and they represented 14 classes and 12 teachers. Students responded to a questionnaire package (see appendix) measuring autonomysupport, need satisfaction, autonomous motivation perceived competence, effort regulation, absorption, helpseeking, peer-learning, performance and participation in late February, just after that they had received their semester grades. The questionnaire was completed in class with one teacher reading the questions for the students.

\subsection{Measures}

The scales for measuring motivational and learning strategy variables were translated to Norwegian from English following recommended procedures (Beaton, Bombardier, Guillemin, \& Ferraz, 2000). The measures were found reliable in previous research in Norway as well as in the present study. In a past study, $\alpha$ for perceived teacher autonomy support was .96 (Bagøien, Halvari, \& Nesheim, 2010) and in the current study $\alpha$ was .89. For psychological need satisfaction: in a past study the range of $\alpha$ was .78 - .83 for the autonomy need; $.78-.84$ for 
the competence need; and .82 - .88 for the relatedness need (Solberg, Hopkins, Ommundsen, \& Halvari, 2012). In the current study, $\alpha=.85$ for the autonomy need, $\alpha=.88$ for the competence need, and $\alpha=.87$ for the relatedness need. In a past study, the autonomous motivation for learning had an $\alpha=.92$ (Bagøien et al., 2010); and in the current study, $\alpha=.80$ (with $\alpha$ 's $=.93$ and .88 for the intrinsic and identified motivation sub-scales, respectively). For perceived competence, $\alpha=.95$ (Bagøien et al., 2010); and in the current study $\alpha=.89$.

Regarding the learning strategy scales, they were found acceptably reliable in the current study ( $\alpha$ 's $=.73$ for effort regulation, .73 for peer learning, and with a borderline estimate of .64 for help seeking). This pattern of internal consistency is the same as initially reported for these scales, with $\alpha$ 's $=.69$ for effort regulation, 76 for peer learning, and .52 for help-seeking (Pintrich, Smith, Garcia, \& McKeanchie, 1991). For absorption, $\alpha=.72$ in the current study.

\subsection{Data Analysis}

Before we tested the hypothesized SDT process model and because students were nested within teachers, we used multilevel hierarchical linear modeling (HLM, Version 7.00; Raudenbush, Bryk, \& Congdon, 2010) to test whether teacher differences affected students' self-reported perceptions of autonomy support, needs satisfaction, motivation, learning strategies, and performance. The percentage of the total variance explained by teacher was low for all student indicators, except for the two performance indicators, which exceeded the $10 \%$ cutoff value as reflected by the intraclass correlation coefficient (ICC; see the first column in Table 1). Due to the low number of between-teacher differences on the indicator level (i.e., 2 out of 21) and the low number of clusters (i.e., 12 teachers), we decided to perform two structural equation tests with Mplus (Version 7.3; Muthén \& Muthén, 1998-2012). First, we tested the complete SDT process model, with its seven latent variables, as an ordinary covariance-based structural equation model. Next, we utilized multilevel structural equation modeling on a reduced model that included only two latent variables, namely learning strategies and performance. The decision to test only a reduced multilevel model was based on the fact that the number of clusters to analyze (i.e., 12) was relatively low for the performance of a valid multilevel analysis (McNeish \& Stapleton, 2014). As emphasized above, the ICC from the HLM analysis revealed that the performance indicators were the only indicators that were exposed to a between-teacher effect. This suggests that it is only necessary to test the relations between learning strategies and performance as a multilevel model. Testing two different models, namely, one ordinary and one multilevel model, makes it possible to compare the influence of between-teacher effects on the relations between learning strategies and performance.

The model fit in Mplus was evaluated by using the chi-square likelihood ratio $\left(\mathrm{X}^{2}\right)$, the Tucker Lewis Index (TLI), the Comparative Fit Index (CFI), the standardized root-mean-square residual (SRMR), and the root mean square error of approximation (RMSEA). TLI and CFI values should be close to .95 or higher to be adequate, and the values for SRMR and RMSEA should be equal to or lower than .08 (Hu \& Bentler, 1999). If the values are close to these recommendations, the fit of the hypothesized model to the data would be considered adequate. These values for model evaluation are also reported in other studies describing good or acceptable fit (Schermelleh-Engel, Moosbrugger, \& Muller, 2003).

\section{Results}

\subsection{Descriptive Statistics and Reliability}

In Table 2, observed ranges, standard deviations, and means are presented together with reliabilities for all the variables. All of the variables yielded good reliability estimates exceeding the value of .70, except the help seeking variable with an alpha value $=.64$. Pintrich et al. (1993) reported an alpha value $=.52$ for help seeking, arguing that it can be because the items ask about seeking help both from peers and instructors, and that students tend to seek help from only one of these sources.

\subsection{Measurement Model}

We tested the measurement model with all the variables and found an adequate fit. $\left[\mathrm{X}^{2}=448.36, \mathrm{df}=174, p\right.$ $<.001 ; \mathrm{TLI}=.91 ; \mathrm{CFI}=.93 ; \mathrm{SRMR}=.058 ; \mathrm{RMSEA}=.074]$. One out of twenty-two indicators was dropped (cf., Table 1) based on reported standardized residuals. This means that this indicator showed a significant degree of shared nonspecified variance with other measurement items. After removing this indicator, the model fit 
Table 1. Interclass correlation coefficients (ICC), standardized beta $(\beta)$ weights and t-values for all 22 observed indicators.

\begin{tabular}{|c|c|c|c|}
\hline Observed variable & ICC (\%) & $\beta$ & t-value \\
\hline \multicolumn{4}{|l|}{ Perceived autonomy support indicators } \\
\hline 1. Teacher provides choices and options & 0.00 & .71 & $21.47^{* * *}$ \\
\hline 2. Feel understood by my teacher & 0.02 & .81 & $31.36 * * *$ \\
\hline 3. Teacher conveys confidence in me & 0.02 & .78 & $28.44 * * *$ \\
\hline 4. Teacher encourages questions & 0.00 & .67 & $18.38 * * *$ \\
\hline 5. Teacher listens... & 0.04 & .79 & $28.80 * * *$ \\
\hline 6. Teacher understands how I see things ${ }^{1}$ & 0.03 & .75 & $24.57 * * *$ \\
\hline \multicolumn{4}{|l|}{ Needs satisfaction indicators } \\
\hline 1. Competence need & 0.00 & .95 & $80.76^{* * *}$ \\
\hline 2. Social relatedness need & 0.00 & .72 & $23.34 * * *$ \\
\hline 3. Autonomy need & 0.00 & .84 & $41.36^{* * *}$ \\
\hline \multicolumn{4}{|l|}{ Autonomous motivation indicators } \\
\hline 1. Intrinsic motivation & 0.06 & .92 & $40.54 * * *$ \\
\hline 2. Identified motivation & 0.02 & .80 & $28.37 * * *$ \\
\hline \multicolumn{4}{|l|}{ Perceived competence indicators } \\
\hline 1. PC1 & 0.00 & .80 & $32.33 * * *$ \\
\hline 2. PC2 & 0.00 & .85 & $43.39 * * *$ \\
\hline 3. PC3 & 0.00 & .73 & $24.27 * * *$ \\
\hline 4. PC4 & 0.00 & .88 & $51.61 * * *$ \\
\hline \multicolumn{4}{|l|}{ Learning strategy indicators } \\
\hline 1. Effort regulation & 0.02 & .68 & $18.20 * * *$ \\
\hline 2. Absorption & 0.06 & .61 & $14.36^{* * *}$ \\
\hline 3. Peer learning & 0.02 & .67 & $16.54 * * *$ \\
\hline 4. Help seeking & 0.00 & .52 & $10.19 * * *$ \\
\hline \multicolumn{4}{|l|}{ Performance indicators } \\
\hline 1. Actual grade & 0.20 & .78 & $23.07^{* * *}$ \\
\hline 2. Expected grade & 0.11 & .87 & $29.71 * * *$ \\
\hline \multicolumn{4}{|l|}{ Participation indicator } \\
\hline 1. How often participating & 0.01 & -- & -- \\
\hline
\end{tabular}

improved slightly $\left[\mathrm{X} 2^{2}=375.05, \mathrm{df}=155, p<.001 ; \mathrm{TLI}=.92 ; \mathrm{CFI}=.94 ;\right.$ SRMR $\left.=.051 ; \mathrm{RMSEA}=.070\right]$.

\subsection{Structural Equation Model}

The theoretical model with all the hypothesized paths was tested as a structural equation model based on the hypothesized relations between latent variables. In the theoretical structural model, all paths were significant, and the model yielded an adequate fit $[\mathrm{X} 2=431.89$, $\mathrm{df}=182, p<.001$; TLI $=.92$; CFI $=.93$; SRMR $=.059$; RMSEA = .069].

\subsection{Test of Indirect Links}

We used Mplus to simultaneously test the indirect links in the structural model presented in Figure 1: (1) Autonomy support was indirectly positively associated with both autonomous motivation $(\mathrm{E}=.45, \mathrm{SE}=.04, \mathrm{Z}=$ $10.53)$ and perceived competence $(E=.50, S E=.04, Z=11.82)$ through need satisfaction; $(2)$ need satisfaction 


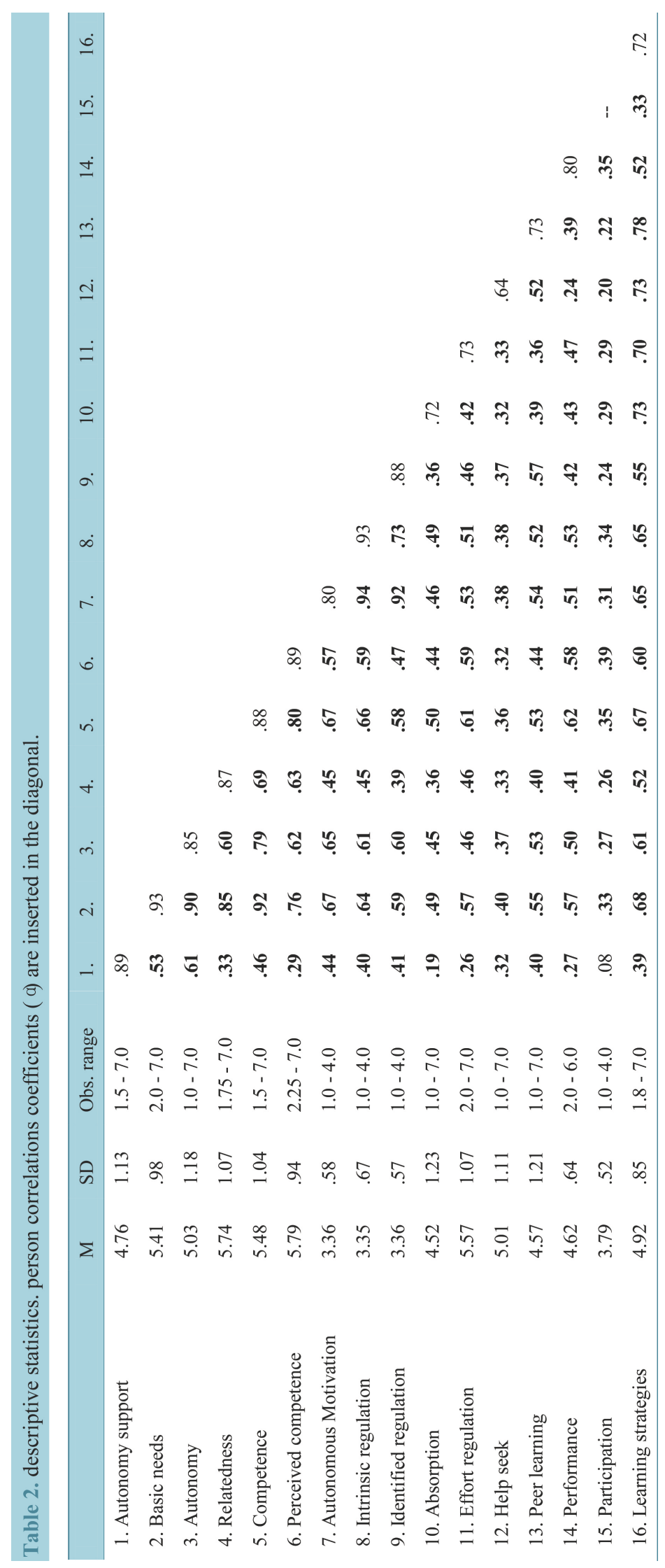


was indirectly linked to learning strategies through both autonomous motivation $(\mathrm{E}=.43, \mathrm{SE}=.06, \mathrm{Z}=7.31)$ and perceived competence ( $\mathrm{E}=.41, \mathrm{SE}=.06, \mathrm{Z}=6.88$ ); and (3) autonomous motivation and perceived competence were each separately indirectly linked to both participation and performance, respectively, through learning strategies. Autonomous motivation with $\mathrm{E}=.23, \mathrm{SE}=.04, \mathrm{Z}=6.02$ upon participation and $\mathrm{E}=.43, \mathrm{SE}=.05$, $\mathrm{Z}=7.94$ upon performance. Perceived competence with $\mathrm{E}=.21, \mathrm{SE}=.04, \mathrm{Z}=5.30$ upon participation, and $\mathrm{E}$ $=.38, \mathrm{SE}=.06, \mathrm{Z}=6.73$ upon performance. All scores were significant at the .001 level.

\subsection{Multilevel Structural Equation Modeling}

In multilevel structural equation modeling, Mplus calculates parameter values and model fit by distributing variance at both the student (Level 1 and WITHIN effects, $n=290$ ) and teacher (Level 2 and BETWEEN effects, $n$ $=12$ ) levels and by partitioning the Standardized Root Mean Square Residual (SRMR) value into these two sources of information.

Running Mplus multilevel analysis on a model composed of learning strategies and performance, generated a SRMR value of 0.05 for the WITHIN level and 0.19 for the BETWEEN level. This indicate that the WITHIN level model has adequate fit while the BETWEEN model has relatively poor fit. The WITHIN standardized beta coefficient (i.e., where the teacher-effect is controlled for, was .74 $(p<.001)$. Compared with the effect from the regular Mplus analysis (cf., Figure 1) this means that the standardized beta coefficient decrease from .79 to .74 when we controlled for the teacher effect. Our conclusion is that the standardized beta coefficients reported in Figure 1 were in general valid. The only exception from this was that the beta coefficient between learning strategies and performance should be marginally corrected (i.e., from .79 to .74).

When we tested the contribution of normative ability (grades) together with autonomous motivation and perceived competence in relation to the use of learning strategies the standardized beta coefficient from perceived competence decreased from .48 to .28. For autonomous motivation, the correlation went up from .55 to .60, and for normative ability (grades) it became .35. All coefficients were significant at the .001 level. Compared with the theoretical structural model, we got a weaker fit. $\left[\mathrm{X}^{2}=551.39, \mathrm{df}=182, \mathrm{p}<.001\right.$; TLI $=.88$; CFI $=.90$; SRMR $=.107 ;$ RMSEA $=.084]$.

Except the path from perceived competence to help seeking, significant path coefficients are presented (see Table 3) between each of the two motivation variables and each of the four learning strategy variables, which in the same model test predicted each of the two dependent variables of participation and performance.

\section{Discussion}

This study supports the SDT (Deci \& Ryan, 2000) process model of participation and performance in physical education. As hypothesized, links from autonomy support to need satisfaction and from need satisfaction to autonomous motivation and perceived competence were significant. Links from both autonomous motivation and perceived competence to learning strategies, and from learning strategies to performance and participation in physical education were significant. All indirect links in the structural model were also significant. Autonomy support is defined as behavior to nurture and develop students' inner motivational resources (Reeve, 2009). Satisfactions of the three needs are central resources and, as hypothesized, perceived autonomy support is important for nurturing the need for competence, autonomy, and relatedness. Autonomy support correlated with all of

Table 3. Mplus path coefficients between independent motivation variables and the four mediating learning strategy variables, and between the learning strategy variables and the dependent participation and performance variables. ${ }^{* * *} p<.001$; ${ }^{* *} p<.005 ;{ }^{*} p<0.05 ;$ ns = not significant.

\begin{tabular}{ccccc}
\hline \multirow{2}{*}{ Mediator Variables } & \multicolumn{2}{c}{ Independent Variables } & \multicolumn{2}{c}{ Dependent Variables } \\
\cline { 2 - 5 } & $\begin{array}{c}\text { Autonomous } \\
\text { Motivation }\end{array}$ & Perceived Competence & Participation & Performance \\
\hline Absorption & $.37^{* * *}$ & $.24^{* * *}$ & $.28^{* * *}$ & $.52^{* * *}$ \\
Effort regulation & $.28^{* * *}$ & $.44^{* * *}$ & $.30^{* * *}$ & $.55^{* * *}$ \\
Peer learning & $.50^{* * *}$ & $.15^{*}$ & $.23^{* * *}$ & $.46^{* * *}$ \\
Help seeking & $.35^{* * *}$ & $.10^{\mathrm{ns}}$ & $.20^{* * * *}$ & $.32^{* * * *}$ \\
\hline
\end{tabular}


the three needs independently, and the three needs were then brought together as a single construct. This underpins the importance of providing autonomy support to students because of the nurturing of the needs that is central to human growth and development (Ryan \& Deci, 2002). By focusing on the five aspects of autonomy supportive behavior that is proposed by Reeve (2009), teachers can facilitate satisfaction of the three needs that work as a mediator from autonomy support to autonomous motivation and perceived competence. Becoming more autonomously motivated and perceiving more competence have a range of positive effects in physical education (Cheon et al., 2012; Vallerand \& Bissonette, 1992; Grolnick, Ryan, \& Deci, 1991; Miserandino, 1996; Bagøien \& Halvari, 2005).

Results indicated that needs satisfaction is important to understand the processes through which autonomy support relates to autonomous motivation, perceived competence, and learning strategy use. In line with earlier research (Ntoumanis, 2005) satisfaction of the three needs was used as one variable in the analyses to simplify the model. As shown in Table 2, all of the three needs showed high correlations with autonomous motivation, perceived competence, and all of the four learning strategies. This gives support to the hypothesis that all of the three needs are important for students to become more autonomously motivated (Ntoumanis, 2005) and to experience more perceived competence (Bagøien, Halvari, \& Nesheim, 2010).

Students with high normative ability have been shown to use learning strategies more often (Ames \& Archer, 1988). We controlled for grades when examining the relations from autonomous motivation and perceived competence to learning-strategy use. We found that autonomous motivation was the most important factor for using learning strategies. By controlling for grades we saw that autonomous motivation and perceived competence were important for all students' learning-strategy use regardless of high or low ability. In addition, in our main model, learning strategies predicted grades the most strongly. That is good news for those low in performance but high in autonomous motivation. By being autonomy supportive, teachers can influence students' motivation, which would positively affect the use of learning strategies and the receipt of higher grades.

In attribution theory (Weiner, 1979), ability is seen as a relatively more stable factor than effort, and thus more difficult to change than motivation. Therefore, we advocate the strategy of providing autonomy support to enhance students' motivation and makes them able to start using learning strategies that can change their performance because learning strategies are important for learning and competence development (Weinstein \& Mayer, 1986). Students using the learning strategies of effort regulation, absorption, peer learning, and help seeking in physical education classes, participate more and show better performance. Often students meet activities they do not enjoy. Being able to use learning strategies becomes an important strategy to be able to perform and participate in physical education. Peer learning and help seeking supports students when they encounter challenges or problems they cannot solve on their own.

It may be especially important for those who are low performers to use these strategies, but they may not know how to find help or may not be motivated to do so (Crede \& Phillips, 2011). Regarding high performing students the case may be that they do not need help, and in that regard do not use that strategy. In a review by Crede \& Phillips (2011), they found peer learning and help seeking to be unrelated to academic performance. They were looking at studies from economics, science, mathematics, medicine, and English. They also stated that learning strategies are class-specific and vary across classes for the same individual. In the current study, we did see significant correlations between these strategies and performance and participation. Peer learning and help seeking was important for participation and performance in physical education. One reason can be the nature of physical education. It is a setting where students work together, collaborate, and are required to use these learning strategies. It may also be that, if they get their needs supported from autonomy supportive teachers, they may be confident to seek help from peers and teachers.

Effort regulation is important for academic success and for continued use of learning strategies (Pintrich et al., 1991). Effort is seen in Norway as a basis for assessing grades in physical activity. In that regard, this study gives insight into variables that directly influence students' grades. Getting knowledge about how to influence effort regulation is important for helping students perform better. We see autonomous motivation and perceived competence together with autonomy support and need satisfaction as important in that process.

In this study, we also saw a mediating role of learning-strategy use in the links from SDT constructs like perceived competence and autonomous motivation to the outcomes of participation and performance. However, perceived competence may be of less importance than autonomous motivation in their links through help seeking to participation and performance.

The four learning strategies were brought together as one variable in the main analyses. However, significant 
positive path coefficients from all of the four strategies upon both performance and participation were shown. The same applies to the relations from autonomous motivation and perceived competence to each of the learning strategies, except the path from perceived competence to help seeking.

There are several limitations in this study. All the data are based on self-reports, which has been criticized because the participants may misunderstand questions or try to gain the teachers approval. To address this we had, when collecting the data, a teacher reads the questions and tries to clarify misunderstandings. Before the questionnaires were delivered the students were told that all their reports would be anonymous and that no teachers would look through them. Still, with self-reports there is also a common variance problem among the measures, which can be avoided with more objective performance measures, longitudinal studies, or experimental designs. However, in the present research we wanted to establish and verify the correlations between the variables in the model tested, before we test the model experimentally in a follow-up study.

\section{Conclusion}

Self-determination theory's motivational constructs of autonomous motivation and perceived competence predicted participation and performance in physical education indirectly through the use of learning strategies such as absorption, effort regulation, peer learning, and help seeking. Autonomy support from teachers was important to nurture the need for competence, autonomy, and relatedness that mediated its relations with the motivational constructs. It was also important for teachers to encourage students to use learning strategies and to teach them how to use these strategies to be able to participate and perform better in school.

\section{References}

Ames, C., \& Archer, J. (1988). Achievement Goals in the Classroom: Students' Learning Strategies and Motivation Processes. Journal of Educational Psychology, 80, 260-267. http://dx.doi.org/10.1037/0022-0663.80.3.260

Bagøien, T. E., \& Halvari, H. (2005). Autonomous Motivation, Involvement in Physical Activity, and Perceived Competence: Structural and Mediator Models. Perseptual and Motor Skills, 100, 3-21. http://dx.doi.org/10.2466/pms.100.1.3-21

Bagøien, T. E., Halvari, H., \& Nesheim, H. (2010). Self-Determined Motivation in Physical Education and Links to Motivation for Leisure-Time Physical Activity, Physical Activity, and Well-Being in General. Perceptual and Motor Skills, 111, 407-432. http://dx.doi.org/10.2466/06.10.11.13.14.PMS.111.5.407-432

Barkoukis, V., Hagger, M. S., Lambropoulos, G., \& Tsorbatzoudis, H. (2010). Extending the Trans-Contextual Model in Physical Education and Leisure-Time Contexts: Examining the Role of Basic Psychological Need Satisfaction. British Journal of Educational Psychology, 80, 647-670. http://dx.doi.org/10.1348/000709910X487023

Beaton, D. E., Bombardier, C., Guillemin, F., \& Ferraz, M. B. (2000). Guidlines for the Process of Cross-Cultural Adaption of Self-Report Measures. SPINE, 25, 3186-3191. http://dx.doi.org/10.1097/00007632-200012150-00014

Chatzisarantis, N. L., \& Hagger, M. S. (2009). Effects of an Intervention Based on Self-Determination Theory on Self-Reported Leisure-Time Physical Activity Participation. Psychology and Health, 24, 29-48. http://dx.doi.org/10.1080/08870440701809533

Cheon, S. H., Reeve, J., \& Moon, I. S. (2012). Experimentally Based, Longitunally Designed, Teacher-Focused Intervention to Help Physical Education Teachers Be More Autonomy Supportive Toward Their Students. Journal of Sport \& Exercise Psychology, 34, 365-396.

Crede, M., \& Phillips, L. A. (2011). A Meta-Analytic Review of the Motivated Strategies for Learning Questionnaire. Learning and Individual Differences, 21, 337-346. http://dx.doi.org/10.1016/j.lindif.2011.03.002

Cury, A., Elliot, A., Sarrazin, P., Da Fonseca, D., \& Rufo, M. (2002). The Trichotomous Achievement Goal Model and Intrinsic Motivation: A Sequential Mediational Analysis. Journal of Experimental Social Psycology, 38, 473-481. http://dx.doi.org/10.1016/S0022-1031(02)00017-3

Deci, E. L., \& Ryan, R. M. (2000). The "What” and "Why” of Goal Pursuite: Human Needs and the Self-Determination of Behavior. Psychological Inquiry, 11, 227-268. http://dx.doi.org/10.1207/S15327965PLI1104_01

Deci, E. L., \& Ryan, R. M. (2008). Self-Determination Theory: A Macrotheory of Human Motivation, Development, and Health. Canadian Psychology, 49, 182-185. http://dx.doi.org/10.1037/a0012801

Dweck, C. (1999). Self-Theories: Their Role in Motivation, Personality and Development. Philadelphia: Taylor \& Francis.

Elliot, A. J., Murayama, K., \& Pekrun, R. (2011). A $3 \times 2$ Achievement Goal Model. Journal of Educational Psychology, 103, 632-648. http://dx.doi.org/10.1037/a0023952

Grolnick, W. S., Ryen, R. M., \& Deci, E. L. (1991). Inner Resources for School Achievement: Motivational Mediators of 
Children's Perceptions of Their Parents. Journal of Educational Psychology, 83, 508-517. http://dx.doi.org/10.1037/0022-0663.83.4.508

Halvari, H., Ulstad, S. O., Bagøien, T. E., \& Skjesol, K. (2009). Autonomy Support and It’s Links to Physical Activity and Competitive Performance: Mediation through Motivation, Competence, Action Orientation and Harmonious Passion, and the Moderator Role of Autonomy Support by Perceived Competence. Scandinavian Journal of Educational Research, 53, 535-555. http://dx.doi.org/10.1080/00313830903302059

Hardre, P. L., \& Reeve, J. (2003). A Motivational Model of Rural Students’ Intension to Persist in, versus Drop Out of, High School. Journal of Educational Psychology, 95, 147-356. http://dx.doi.org/10.1037/0022-0663.95.2.347

Hofer, B., Yu, S., \& Pintrich, P. R. (1998). Teaching College Students to be Self-Regulated Learners. In D. H. Schunk, \& B. J. Zimmermann (Eds.), Self-Regulated Learning: From Teaching to Self-Reflective Practice (pp. 57-85). New York: Guilford.

Hu, L., \& Bentler, P. M. (1999). Cutoff Criteria for Fit Indexes in Covariance Structure Analysis: Conventional Criteria versus New Alternatives. Structural Equation Modeling: A Multidisciplinary Journal, 6, 1-55. http://dx.doi.org/10.1080/10705519909540118

Koka, A., \& Hagger, M. S. (2010). Perceived Teaching Behaviors and Self-Determined Motivation in Physical Education: A Test of Self-Determination Theory. Research Quarterly for Exercise and Sport, 81, 74-86. http://dx.doi.org/10.1080/02701367.2010.10599630

Komarraju, M., \& Nadler, D. (2013). Self-Efficacy and Academic Achievement: Why Do Implicit Beliefs, Goals, and Effort Regulation Matter? Learning and Individual Differences, 25, 67-72. http://dx.doi.org/10.1016/j.lindif.2013.01.005

Kusurkar, R. A., Ten Cate, T. J., Vos, C. M., Westers, P., \& Croiset, G. (2012). How Motivation Affects Academic Performance: A Structural Equation Modelling Analysis. Advances in Health Sciences Education. Theory and Practice, 18, 57-69.

Lee, F. K., Sheldon, K. M., \& Turban, D. B. (2003). Personality and the Goal-Striving Process: The Influence of Achievement Goal Patterns, Goal Level, and Mental Focus on Performance and Enjoyment. Journal of Applied Psychology, 88, 256-265. http://dx.doi.org/10.1037/0021-9010.88.2.256

Lynch, D. J. (2006). Motivational Factors, Learning Strategies and Resource Management as Predictors of Course Grades. College Student Journal, 40, 423-428.

Lynch, D. J. (2010). Motivational Beliefs and Learning Strategies as Predictors of Academic Performance in College Physics. College Student Journal, 44, 920-927.

Martin, A. J., \& Jackson, S. A. (2008). Brief Approaches to Assessing Task Absorption and Enhanced Subjective Experience: Examining “Short” and “Core” Flow in Diverse Performance Domains. Motivation and Emotion, 32, 141-157. http://dx.doi.org/10.1007/s11031-008-9094-0

McNeish, D., \& Stapleton, L. (2014). The Effect of Small Sample Size on Two-Level Model Estimates: A Review and Illustration. Educational Psychological Review, 1-20. http://dx.doi.org/10.1007/s10648-014-9287-x

Miserandino, M. (1996). Children Who Do Well in School: Individual Differences in Perceived Competence and Autonomy in Above-Average Children. Journal of Educational Psychology, 88, 203-214. http://dx.doi.org/10.1037/0022-0663.88.2.203

Moreno, J. A., González-Cutre, D., Martín-Albo, J., \& Cervelló, E. (2010). Motivation and Performance in Physical Education: An Experimental Test. Journal of Sports Science and Medicine, 9, 79-85.

Moreno-Murcia, J. A., Lacarcel, J. A., \& Alvarez, F. D. (2010). Search for Autonomy in Motor Task Learning in Physical Education University Students. European Journal of Psychology of Education, 25, 37-47.

http://dx.doi.org/10.1007/s10212-009-0008-7

Muthén, L., \& Muthén, B. (1998-2012). Mplus User’s Guide (7th ed.). Los Angeles, CA: Muthén \& Muthén.

Niemiec, C. P., \& Ryan, R. M. (2009). Autonomy, Competence, and Relatedness in the Classroom. Applying Self-Determination Theory to Educational Practice. Theory and Research in Education, 7, 133-144.

http://dx.doi.org/10.1177/1477878509104318

Nisbet, J., \& Shucksmith, J. (1986). Learning Strategies. London: Routledge Education Books.

Noels, K. A., Clement, R., \& Pelletier, L. G. (1999). Perception of Teachers’ Communicative Style and Students’ Intrinsic and Extrinsic Motivation. The Modern Language Journal, 83, 23-34. http://dx.doi.org/10.1111/0026-7902.00003

Ntoumanis, N. (2001). A Self-Determination Approach to the Understanding of Motivation in Physical Education. British Journal of Educational Psychology, 71, 225-242. http://dx.doi.org/10.1348/000709901158497

Ntoumanis, N. (2002). Motivational Clusters in a Sample of British Physical Education Classes. Psychology of Sport and Exercise, 3, 177-194. http://dx.doi.org/10.1016/S1469-0292(01)00020-6

Ntoumanis, N. (2005). A Prospective Study of Participation in Optional School Physical Education Using a Self-Determina- 
tion Theory Framework. Journal of Educational Psychology, 97, 444-453.

http://dx.doi.org/10.1037/0022-0663.97.3.444

Ntoumanis, N., \& Standage, M. (2009). Motivation in Physical Education Classes. A Self-Determination Theory Perspective. Theory and Research in Education, 7, 194-202. http://dx.doi.org/10.1177/1477878509104324

Pintrich, P. R. (1999). The Role of Motivation in Promoting and Sustaining Self-Regulated Learning. International Journal of Educational Research, 31, 459-470. http://dx.doi.org/10.1016/S0883-0355(99)00015-4

Pintrich, P. R. (2000). The Role of Goal-Orientation in Self-Regulated Learning. In M. Boekaerts, P. R. Pintrich, \& M. Zeidner (Eds.), Handbook of Self-Regulation (pp. 451-502). San Diego, CA: Academic Press. http://dx.doi.org/10.1016/b978-012109890-2/50043-3

Pintrich, P. R., Smith, D. A., Garcia, T., \& McKeachie, W. J. (1993). Reliability and Predictive Validity of the Motivated Strategies for Learning Questionnaire (MSLQ). Educational and Psychological Measurement, 53, 801-813. http://dx.doi.org/10.1177/0013164493053003024

Pintrich, P. R., Smith, D. A., Garcia, T., \& McKeanchie, W. J. (1991). A Manual for the Use of the Motivated Strategies for Learning Questionnaire (MSLQ). Ann Arbor, MI: National Center for Research to Improve Postsecondary Teaching and Learning, University of Michigan.

Raudenbush, S. W., Bryk, A. S., \& Congdon, R. (2010). HLM 7.00 for Windows. Lincolnwood, IL: Scientific Software International, Inc.

Reeve, J. (2009). Why Teachers Adopt a Controlling Motivating Style toward Students and How They Can Become More Autonomy Supportive. Educational Psychologist, 44, 159-175. http://dx.doi.org/10.1080/00461520903028990

Ryan, R. M., \& Conell, J. P. (1989). Perceived Locus of Causality and Internalization: Examining Reasons for Acting in Two Domains. Journal of Personality and Social Psychology, 57, 749-761. http://dx.doi.org/10.1037/0022-3514.57.5.749

Ryan, R. M., \& Deci, E. L. (2000). Self-Determination Theory and the Facilitation of Intrinsic Motivation, Social Development, and Well-Being. American Psychologist, 55, 68-78. http://dx.doi.org/10.1037/0003-066X.55.1.68

Ryan, R. M., \& Deci, E. L. (2002). Overview of Self-Determination Theory: An Organismic Dialectical Perspective. In E. L. Deci, \& R. M. Ryan (Eds.), Handbook of Self-Determination Research (pp. 3-33). Rochester, NY: The University of Rochester Press.

Ryan, R. M., Williams, G. C., Patrick, H., \& Deci, E. L. (2009). Self-Determination Theory and Physical Activity: The Dynamics of Motivation in Development and Wellness. Hellenic Journal of Psychology, 6, 107-124.

Schermelleh-Engel, K., Moosbrugger, H., \& Muller, H. (2003). Evaluating the Fit of Structural Equation Models: Tests of Significance and Descriptive Goodness-of-Fit Measures. Methods of Psychological Research, 8, 23-74.

Schunk, D. H. (2005). Self-Regulated Learning: The Educational Legacy of Paul R. Pintrich. Educational Psychologist, 40, 85-94. http://dx.doi.org/10.1207/s15326985ep4002_3

Shang, R. A., Chen, Y. C., \& Shen, L. (2005). Extrinsic versus Intrinsic Motivations for Consumers to Shop On-Line. Information \& Management, 42, 401-413. http://dx.doi.org/10.1016/j.im.2004.01.009

Sheldon, K. M., \& Elliot, A. J. (1998). Not All Personal Goals Are Personal: Comparing Autonomous and Controlled Reasons for Goals as Predictors of Effort and Attainment. Personality and Social Psychology Bulletin, 24, 546-557. http://dx.doi.org/10.1177/0146167298245010

Solberg, P. A., Hopkins, W. G., Ommundsen, Y., \& Halvari, H. (2012). Effects of Three Training Types on Vitality among Older Adults: A Self-Determination Theory Perspective. Psychology of Sport and Exercise, 13, 407-417.

http://dx.doi.org/10.1016/j.psychsport.2012.01.006

Standage, M., \& Gillison, F. (2007). Students' Motivational Responses toward School Physical Education and Their Relationship to General Self-Esteem and Health-Related Quality of Life. Psychology of Sport and Exercise, 8, 704-721. http://dx.doi.org/10.1016/j.psychsport.2006.12.004

Standage, M., Duda, J. L., \& Ntoumanis, N. (2006). Students’ Motivational Processes and Their Relationship to Teacher Ratings in School Physical Education: A Self-Determination Approach. Research Quarterly for Exercise and Sport, 77, 100-110. http://dx.doi.org/10.1080/02701367.2006.10599336

Standage, M., Gillison, F. B., Ntoumanis, N., \& Treasure, D. C. (2012). Predicting Students’ Physical Activity and HealthRelated Well-Being: A Prospective Cross-Domain Investigation of Motivation and Exercise Settings. Journal of Sport \& Exercise Psychology, 34, 37-60.

Taylor, I. M., Ntoumanis, N., Standage, M., \& Spray, C. M. (2010). Motivational Predictors of Physical Education Students' Effort, Exercise Intentions, and Leisure-Time Physical Activity: A Multilevel Linear Growth Analysis. Journal of Sport \& Exercise Psychology, 32, 99-120.

Tessier, D., Sarrazin, P., \& Ntoumanis, N. (2010). The Effect of an Intervention to Improve Newly Qualified Teachers’ Interpersonal Style, Students Motivation and Psychological Need Satisfaction in Sport-Based Physical Education. Contem- 
porary Educational Psychology, 35, 242-253. http://dx.doi.org/10.1016/j.cedpsych.2010.05.005

Vallerand, R. J., \& Bissonnette, R. (1992). Intrinsic, Extrinsic, and Amotivational Styles as Predictors of Behavior: A Prospective Study. Journal of Personality, 60, 599-620. http://dx.doi.org/10.1111/j.1467-6494.1992.tb00922.x

Vlachopoulos, S. P., \& Michailidou, S. (2006). Development and Initial Validation of a Measure of Autonomy, Competence, and Relatedness in Exercise: The Basic Psychological Needs in Exercise Scale. Measurement in Physical Education and Exercise Science, 10, 179-201. http://dx.doi.org/10.1207/s15327841mpee1003_4

Weiner, B. (1979). A Theory of Motivation for Some Classroom Experiences. Journal of Educational Psychology, 71, 3-25. http://dx.doi.org/10.1037/0022-0663.71.1.3

Weinstein, C. E., \& Mayer, R. E. (1986). The Teaching of Learning Strategies. In M. Wittrock (Ed.), The handbook of Research on Teaching (pp. 315-327). New York: Macmillan.

Wild, T. C., Kuiken, D., \& Schopflocher, D. (1995). The Role of Absorption in Experiential Involvement. Journal of Personality and Social Psychology, 69, 569-579. http://dx.doi.org/10.1037/0022-3514.69.3.569

Williams, G. C., \& Deci, E. L. (1996). Internalization of Biopsychosocial Values by Medical Students: A Test of Self-Determination Theory. Journal of Personality and Social Psychology, 70, 767-779. http://dx.doi.org/10.1037/0022-3514.70.4.767

Williams, G. C., Saizow, R., Ross, L., \& Deci, E. L. (1997). Motivation Underlying Career Choice for Internal Medicine and Surgery. Social Science and Medicine, 45, 1705-1713. http://dx.doi.org/10.1016/S0277-9536(97)00103-2

\section{Appendixes}

\section{Questionnaires}

\subsection{Autonomy Support}

Perceived autonomy support was measured with the six-item short version of the Learning Climate Questionnaire (LCQ; Williams \& Deci, 1996). A sample item: "I feel that my teacher provides me with choices and options in PE". Participants responded to the items on a 7-point Likert-scale ranging from 1 (strongly disagree) to 7 (strongly agree).

\subsection{Need Satisfaction}

Psychological need satisfaction was measured with the 12-item "Basic Psychological Needs in Exercise Scale" (BPNES; Vlachopoulos \& Michailidou, 2006), with 4 items measuring each of the three needs (i.e., the needs for competence, relatedness, and autonomy). Three sample items are "I feel very much at ease with the other participants in physical education” (relatedness), "I feel I have been making huge progress with respect to the end result I pursue in physical education" (competence), and "physical education is highly compatible with my choices and interests" (autonomy). Participants responded to the items on a 7-point Likert-scale ranging from 1 (not true at all) to 7 (very true).

\subsection{Motivation}

Autonomous motivation was measured with a slightly adapted version of the 14-item Self-Regulation Questionnaire (SRQ; Ryan \& Conell, 1989). According to theory, items measuring identified and intrinsic types of motivation form autonomous motivation. The students were asked to respond to reasons why they participate in physical education. The 4 stems for the questions were: "Why do you participate in physical education?" "Why do you work hard in physical education?" "Why do you train at difficult things in physical education?" and "Why do you wish to do well in physical education?" Sample items are: "I participate because": "It's fun" (intrinsic regulation); and "I want to learn and understand more" (identified regulation). Participants responded to the items on a 4-point Likert-type scales ranging from 1 (not true at all) to 4 (very true).

\subsection{Perceived Competence}

Perceived competence was measured with the 4-item Perceived Competence Scale (PCS; Williams \& Deci, 1996). A sample item is: "I feel confident in my ability to manage physical education at school". Participants responded to the items on a 7-point Likert-scale ranging from 1 (strongly disagree) to 7 (strongly agree). 


\subsection{Learning Strategies}

Learning strategies was measured with three resource management strategies from the Motivated Strategies for Learning Questionnaire (MSLQ; Pintrich, Smith, Garcia, \& McKeanchie, 1991), namely, effort regulation, peer learning, and help seeking. Sample items are: "Even when tasks in physical education are dull and uninteresting, I manage to keep working until I finish" (effort regulation); "I try to work with other students from this class to complete the tasks and activities" (peer learning); and "When I can't understand the tasks and exercises in physical education, I ask another student in this class for help" (help seeking).

A fourth learning strategy, absorption, was measured with the 3-item Absorption Scale (Elliot, Murayama, \& Pekrun, 2011). Absorption involves students using the time in class to concentrate on appropriate tasks, which is an attention of control that can be related to the resource management learning strategy labeled time and study environment regulation (Pintrich et al., 1991). A sample item: "In this physical education class I am concentrated on fulfilling the tasks”. Participants responded to the items on a 7-point Likert-type scale ranging from 1 (strongly disagree) to 7 (strongly agree).

\subsection{Participation}

Participation in physical education was measured by one question about how often the students participate in physical education on a scale ranging from 1 (almost never) to 4 (very often). Students are expected to participate in PE, but many come up with different excuses not to. This becomes a problem for the student in reaching the goals in the curriculum, and it becomes a problem for the teachers when assessing grades. Often students come to class and get registered by the teacher, but they are still not participating.

\subsection{Performance}

Performance was measured by self-reported grades and expectation of grades using the following two questions: "What grade did you get last semester in PE?" and "what grade do you expect to get next semester in PE?" Participants responded on a scale ranging from 1 to 6 .

Participants responses within each scale were averaged to reflect the variables used in the analyses. 